\title{
Finding fault: Criticism as a care management strategy and its impact on outcomes for dementia caregivers
}

\author{
Amanda N. Leggett ${ }^{1}$ (D) । Helen C. Kales ${ }^{1}$ | Laura N. Gitlin ${ }^{2,3}$
}

${ }^{1}$ Program for Positive Aging and Department of Psychiatry, University of Michigan, Ann Arbor, Michigan, USA

${ }^{2}$ Dean and Distinguished University Professor, College of Nursing and Health Professions, Drexel University, Philadelphia, Pennsylvania, USA

${ }^{3}$ School of Nursing, Johns Hopkins University, Baltimore, MD, USA

\section{Correspondence}

A. N. Leggett, Program for Positive Aging and Department of Psychiatry, University of

Michigan, Ann Arbor, Michigan, USA.

Email: leggetta@med.umich.edu

Funding information

National Institute on Aging (NIA), Grant/ Award Numbers: K01AG056557, R01AG22254 and R01 AG22254; National Institute on Nursing Research, Grant/Award Number: NCT00259480
Background: Despite a large literature on the stress process, little attention has focused on how caregivers for persons living with dementia (PLWDs) provide care and how this may impact care outcomes. Criticism is a management strategy caregivers may use to respond to behavioral symptoms. We consider whether criticism is associated with caregivers' mental health and service utilization.

Methods: Data are drawn from the Advancing Caregiver Training intervention study including 256 informal caregivers living with a PLWD. In multiple linear regressions controlling for caregivers' demographics and PLWDs' clinical factors, we consider criticism (criticism subscale of the Dementia Management Strategies Scale) as a predictor of caregiver burden, depressive symptoms, desire to institutionalize the PLWD, level of frustration with care, and the number of home-based, social, and health services utilized.

Results: On average, $15 \%$ of the sample sometimes reported using criticism as a management strategy to manage the challenges of care. Greater use of criticism was associated with significantly more caregiver burden $(\beta=0.26, P<0.001)$ and frustration with caregiving ( $\beta=0.66, P<0.001$ ), but not depressive symptoms or a desire to institutionalize the PLWD. Criticism was also associated with significantly greater utilization of home-based $(\beta=0.14, P<0.05)$ and social services $(\beta=0.15$, $P<0.05$ ), but not health care services.

Conclusion: Criticism appears to be used by more burdened and frustrated caregivers. The association of criticism with social and home-based services potentially reflects a need for greater support among this group of caregivers. Behavioral interventions that can help caregivers manage behavioral symptoms with positive, empirically validated strategies may be helpful.

\section{KEYWORDS}

care management, caregiving, criticism, dementia

\section{I INTRODUCTION}

More than 15 million Americans serve in a dementia care role with the care they provide estimated at a total of 18.1 billion hours per year. ${ }^{1}$ The ability of the caregiver to manage the symptoms and changing demands of dementia can impact the well-being and adjustment of the caregiver and the person living with dementia (PLWD) and whether the PLWD can be cared for in the home. Yet despite a large literature on the stress process associated with caregiving for PLWDs, considerably less attention has focused on how caregivers actually manage and provide care, and how the strategies they use may impact their own well-being and care outcomes. Criticism is one form of management caregivers may use either in response to the stresses of care and/or as a strategy to address challenging behaviors. The use of criticism may stem from the incorrect belief that symptoms of dementia are volitional and within the control of the PLWD. ${ }^{2}$ Regardless of 
motivation or underlying reason for using criticism, this strategy is typically ineffective and therefore may have negative consequences for both the caregiver and the PLWD. In the current study, we examine two main questions: whether criticism as a care management strategy is associated with a (1) caregiver's well-being and (2) the caregiver and PLWD's service utilization.

\section{1 | Stress, coping, and criticism}

Research on stress and coping suggests that certain coping strategies are more effective than others. For example, studies generally show poorer adjustment among caregivers using emotion-focused coping strategies such as avoidance, as opposed to problem-focused coping that utilizes more practical ways of managing the stressor. ${ }^{3}$ Criticism, as a specific coping or management strategy, has received notable attention within social science research broadly and the caregiving literature specifically. For example, in his seminal work on marriage and divorce, Gottman coined criticism expressed toward a spousal partner as one of the "four horseman of the apocalypse" in predicting divorce. ${ }^{4}$ In another line of research with family members of individuals with schizophrenia, a literature on expressed emotion (involving criticism, hostility, and emotional over-involvement) has shown that family member' expressed emotion can negatively impact patient outcomes. ${ }^{5}$ In applying this theory to caregivers for PLWDs, it has been found that in contrast with the literature on other mental disorders such as schizophrenia, while expressed emotion may have little effect on the course of dementia (eg, cognitive and functional decline), it may be significantly associated with more behavioral and psychological problems displayed by the individual with dementia over time as well as impacting outcomes for caregivers themselves. ${ }^{6-9}$

Most research concerning how caregivers provide and manage care has examined general coping strategies and personality characteristics of the caregiver and their associations with caregiving outcomes however, as opposed to more situationally specific strategies utilized to manage the unique challenges caregivers confront in managing challenging behaviors. Criticism is one specific management strategy that may be utilized by caregivers for PLWDs. Utilizing pilot interviews with PLWDs and their family members as well as existing clinical literature, The Dementia Management Strategies Scale (DMSS) was developed, which included such constructs as coercion and conflict avoidance. ${ }^{10}$ Later work developed three subscales through factor analytic techniques, which included criticism, encouragement and active management. ${ }^{10,11} \mathrm{~A}$ subscale of the criticism items, including the constructs of coercion and authoritarianism, is used as the key measure in the current study.

\section{2 | Criticism and caregiver well-being}

Prior research has found that negative-type management strategies such as criticism, anger, and lower encouragement are associated with caregiver burden, a desire to institutionalize the PLWD, and less experienced positive aspects of caregiving (eg, fulfillment). 2,10,12-15 These associations tend to persist across cultural contexts (eg, Singapore) and do not appear to occur based on the severity of the dementia,

\section{Key points}

- Among caregivers of persons at the moderate stage of dementia in which hands-on care management increases, we found that one in 10 caregivers used criticism as a strategy to manage the behaviors of a person living with dementia.

- Criticism was associated with caregiver burden and frustration, as well as social and home-based services utilization, independent of the functional, cognitive, and behavioral status of the person living with dementia.

level of functional impairment, cognitive decline, or presence of behavioral and psychological symptoms, as well as characteristics of the caregiver. Furthermore, criticism has been associated with more general, negative coping strategies such as venting, blaming oneself, and self-distraction and may reflect disengagement from the objective stressor. $^{2}$

\section{3 | Criticism and services utilization}

Use of criticism may also be associated with potentially inappropriate service use. For example, Gitlin and colleagues ${ }^{16}$ found that the use of positive dementia-management strategies such as facilitating a safer environment and diverting the attention of persons with dementia (items drawn from a subscale of the DMSS ${ }^{10}$ ) when they were upset were associated with the use of more adaptive behavioral strategies (such as taking rest breaks from activity or using pictures to identify objects in a room; drawn from the Task Management Strategies Inde ${ }^{16}$ ), whereas criticism was not associated with the use of these positive behavioral strategies. Additionally, recent work found that caregivers reporting high levels of distress or burden utilized more acute care services such as emergency department visits as well as other social and health services for both themselves and the PLWD. ${ }^{17-20}$ Martindale-Adams, Nichols, Zuber, Burns, Graney ${ }^{21}$ found that compared with non-service users, caregivers utilizing health and social services for themselves had significantly more burden, depression, upset with behavioral symptoms, and a stronger desire to institutionalize the PLWD.

Further, recent work has shown the criticism management strategy utilized by family caregivers to be associated with the frequency and severity of behavioral and psychological symptoms of dementia in individuals with Alzheimer disease suggesting that criticism may relate to the severity of symptoms and need for services. ${ }^{22}$ However, the strategies that caregivers are using in their home to manage the PLWD have not been considered as correlates of services utilized. Further, unlike caregiving for other chronic medical conditions, caregivers for PLWDs may play a particularly active role in determining services utilized for themselves as well as the PLWD due to the declining cognitive and functional capacity of the PLWD. Ultimately, caregiver management strategies, such as criticism, may be modifiable 
and, through intervention, prevent increased caregiver distress and unnecessary service utilization.

In the current study, we consider criticism as a care management strategy that may be associated with (1) a caregiver's mental health and well-being (burden, depressive symptoms, expressed frustration, and desire to institutionalize the PLWD) and (2) service utilization in three categories: home, social, and health services. We hypothesize that criticism is associated with (a) reduced well-being for the caregiver and (b) greater utilization of supportive services of both the caregiver and PLWD.

\section{2 | METHODS}

Data are drawn from the baseline (pre-intervention) survey from the Advancing Caregiver Training (Project ACT) intervention study, a study designed to test a non-pharmacological approach to help caregivers manage behavioral symptoms they identify as most challenging to them. The analytic sample included 256 of the 272 informal caregivers in the trial (16 participants were deleted from models due to a missing score on the MMSE) living with an individual with diagnosed dementia or a Mini-Mental Status Examination score of less than 24 and who reported experiencing "upset" related to management of behavioral problems. Caregivers were managing care for persons at the moderate stage of dementia and had expressed challenges in managing behavioral symptoms. The study was approved by the Johns Hopkins University Institutional Review Board and informed consent was obtained from all participants.

\section{1 | Measures}

\subsection{1 | Demographics}

Age, gender, race (white, black, and other), spousal caregiver (versus non-spousal caregiver), and level of education (less than high school, high school, greater than high school) were included as demographic controls in all models.

\subsection{2 | Caregiver-specific covariate}

Caregiver's upset with behavioral symptoms was a sum of caregiver's rated upset $(0=$ no upset to $10=$ extreme upset) for up to 23 PLWD' behavioral problems drawn from standardized scales (possible range 0 to 230$)^{23-25}$

\subsection{3 | Person living with dementia specific covariates}

The Mini-Mental State Examination (MMSE), a 30-point scale assessing cognitive abilities (memory, orientation and arithmetic), was used as a measure of care receiver cognitive function with a lower score indicating greater cognitive impairment. ${ }^{26}$ Activities of daily living (ADLs) and instrumental activities of daily living (IADLs) were assessed with the Caregiver Assessment of Function and Upset scale. ${ }^{27}$ ADLs (eg, dressing) was a count of seven possible functional care tasks a PLWD needed support with and IADLs (eg, food preparation) was a count of eight possible tasks.

\subsection{4 | Criticism}

Criticism was measured as a mean score on a four-item subscale (I criticized or scolded my CR to try to prompt better behavior from him/her, I threatened by CR with undesirable consequences if he/she did not cooperate, I withdrew from my CR, I yelled or acted enraged; it was often the only way to get my way with him/her) drawn from the Dementia Management Strategies Scale. ${ }^{10}$ Items were on a 5-point scale from never to always (range, 1-5) with a higher score indicating greater expressed criticism toward the PLWD ( $\alpha=0.72$ ).

\subsection{5 | Outcomes related to caregiver and person living with dementia well-being}

We examine the desire of caregivers to institutionalize their PLWD with six yes/no items concerning the last 6 months (eg, in the past 6 months, have you felt your care receiver would be better off in a nursing home?) ( $a=0.67)$. Scores range from zero to six with a higher score indicating a greater desire to institutionalize. ${ }^{28}$ We examined three outcomes concerning caregivers: their level of frustration with caregiving, depressive symptoms, and burden. Frustration was measured as a mean score with the Frustrations of Caregiving scale, which is an eight-item measure from the REACH II battery questioning caregivers about how often in the past 6 months they felt like using harsh measures such as hitting or confining the PLWD $(\alpha=0.74)$. Items were on a 5-point scale from 1 (never) to 5 (always) with a higher score indicating greater frustration (range, 1-5). ${ }^{21}$ For depressive symptoms, we used a 10-item short form of the Center for Epidemiological StudiesDepression Scale (CES-D). ${ }^{29}$ Participants responded on a 4-point scale of 0 (rarely or none of the time) to 3 (most or almost all of the time) with a higher score indicating greater depressive symptoms (range, $0-30)$. The scale showed strong reliability $(a=0.81$ ). The 12 -item Zarit Burden Inventory ( $\alpha=0.88$ ) was used to assess caregiver burden on a 5-point scale from 0 (never) to 4 (always) with a higher score (range, 0 48) indicating greater burden (eg, "Do you feel stressed between caring for your relative and trying to meet other responsibilities for your family or work?"). ${ }^{30}$

\subsection{6 | Service utilization outcomes}

Caregivers were also asked about the formal care and support services they utilized for themselves or their care receiver in support of their care provision for the PLWD. These included a count of five home services (home health aide, meal service, visiting nurse, disruptive behavior manager, and homemaker-helps with meals, shopping, cleaning, etc), five social services (adult day care, support groups, transportation, senior day health program, and overnight respite), and seven past-month health services (eg, hospital admission, rehabilitation facility, physician visits, nurse or physician's assistant, counselor/psychiatrist, lab tests, and private medical services). 


\section{2 | Statistical analysis}

Descriptive statistics were run for all variables. To address our research question regarding whether the caregiver strategy of using criticism was associated with caregiver well-being (burden, depressive symptoms, desire to institutionalize the PLWD, and level of frustration with care), we ran multiple linear regressions controlling for caregivers' demographics and PLWDs' functional and cognitive impairment with expressed criticism as the key predictor. Additionally, we considered whether criticism was associated with the number of services utilized in three categories: home-based, social, and health services, accounting for the same controls. SPSS 24.0 was used for all analyses.

\section{3 | RESULTS}

Caregivers on average were 66.8 years old $(\mathrm{SD}=12.5$; range $=33-95)$; approximately $27 \%(n=68$ ) were African American, and half were caring for a spouse $(n=131)$. Of a possible 23 behavioral problems that a PLWD may exhibit, caregivers reported an average of 9.4 (SD = 3.8; range, 2-19). Upset over these problems was moderate with an average score of 52.9 (SD = 30.2; range, 7-153). On average, $15 \%$ ( $n=37$ ) of the sample used criticism as a management strategy "sometimes" or more frequently. Overall, caregivers had moderate burden $(M=21.2 ; S D=9.4 ;$ range = 1-46; a mean item score of 1.8 indicating caregivers reported feeling burdened "sometimes" on average) and depressive symptoms $(M=9.6 ; S D=5.8$; range $=0-25)$ yet relatively low frustration $(M=2.0 ; S D=0.5$; range $=1-4.5)$ and desire to place the PLWD ( $M=1.1 ; S D=1.3$; range $=0-6)$. On average, caregivers used one home service $(S D=0.9$; range $=0-4)$ and social service $(\mathrm{SD}=1.1$; range $=0-4)$ and two health services $(\mathrm{SD}=1.3$; range $=0$ 6) for themselves or the PLWD in support of their care provision. Full sample characteristics can be found in Table 1.

\section{1 | Relationship of criticism to caregiver well-being}

In regard to our first research question, controlling for demographic characteristics, behavioral symptom upset, and disability of the PLWD, greater use of criticism was associated with significantly more caregiver burden $(\beta=0.22, P<0.001)$ and frustration levels $(\beta=0.62$, $P<0.001$ ), but not with depressive symptoms or a desire to institutionalize the PLWD (see Table 2 for full results).

\subsection{Relationship of criticism to service utilization}

We next considered whether criticism as a management strategy was associated with greater services utilization. Controlling for demographics and level of cognitive and functional disability and behavioral upset, criticism was associated with significantly greater utilization of home-based $(\beta=0.15, P<0.05)$ services and was the only predictor significantly associated with social services $(\beta=0.19, P<0.01$ ), however was not significantly associated with the use of health services (see Table 3 for full results).
TABLE 1 Sample characteristics for persons with dementia and their caregivers $^{a}$

\begin{tabular}{|c|c|c|c|}
\hline & $\mathrm{M}$ or $\%$ & SD & $\begin{array}{l}\text { Range/Scale } \\
\text { Range }\end{array}$ \\
\hline \multicolumn{4}{|l|}{ Care receiver characteristics } \\
\hline MMSE & 12.74 & 8.14 & $0-29 / 0-30$ \\
\hline ADLs & 4.54 & 2.28 & $0-7 / 0-7$ \\
\hline IADLs & 7.59 & 0.92 & $2-8 / 0-8$ \\
\hline \multicolumn{4}{|l|}{ Caregiver characteristics } \\
\hline Age & 66.76 & 12.52 & $35-95$ \\
\hline Male & $18.40 \%$ & & \\
\hline \multicolumn{4}{|l|}{ Race } \\
\hline Black & $26.60 \%$ & & \\
\hline White & $71.10 \%$ & & \\
\hline Other & $2.30 \%$ & & \\
\hline Non-spouse & $48.80 \%$ & & \\
\hline \multicolumn{4}{|l|}{ Education } \\
\hline Less than high school & $9.80 \%$ & & \\
\hline High school & $25.00 \%$ & & \\
\hline Greater than high school & $65.20 \%$ & & \\
\hline Upset over behavioral symptoms ${ }^{\mathrm{b}}$ & 52.89 & 30.23 & $7-153 / 0-230$ \\
\hline Criticism & 2.10 & 0.72 & $1-5 / 1-5$ \\
\hline Burden & 21.25 & 9.40 & $1-46 / 0-48$ \\
\hline CESD score & 9.61 & 5.79 & $0-25 / 0-30$ \\
\hline $\begin{array}{l}\text { Desire to place person living with } \\
\text { dementia }\end{array}$ & 1.07 & 1.27 & $0-5 / 0-6$ \\
\hline Care frustration & 1.95 & 0.51 & $1-4.5 / 1-5$ \\
\hline Home services utilization & 0.92 & 1.02 & $0-4 / 0-5$ \\
\hline Social services utilization & 1.03 & 1.11 & $0-4 / 0-5$ \\
\hline Health services utilization & 2.30 & 1.31 & $0-6 / 0-7$ \\
\hline
\end{tabular}

${ }^{a} \mathrm{n}=256$.

bupset based on an average of $9.36(S D=3.80)$ behavioral problems.

\section{4 | DISCUSSION}

The specific management strategies used by family caregivers in dementia care are understudied, and their impact on critical outcomes for the well-being of both PLWDs and caregivers is not well understood. In this study, we found that among caregivers providing care to individuals at the moderate stage of the disease and expressing challenges regarding behavioral problems in the PLWD, a small percent (15\%) used criticism as an active management strategy. Use of criticism was associated with more burden and frustration in caregivers and had significant implications for service utilization even controlling for behavioral problem upset, as well as the functional and cognitive impairment of the PLWD.

\subsection{Criticism and quality of life}

Though relatively few caregivers in our sample expressed criticism towards the PLWD, its utilization may relate to stigma or the belief that behavioral symptoms of dementia are volitional. Weisman de Mamani, Weintraub, Maura, Martinez de Andino, and Brown ${ }^{31}$ found that caregivers who reported greater perceived stigma relating to their care 
TABLE 2 Predictors of burden, depressive symptoms, desire to institutionalize, and caregiver frustration among caregivers for a person living with dementia ${ }^{a}$

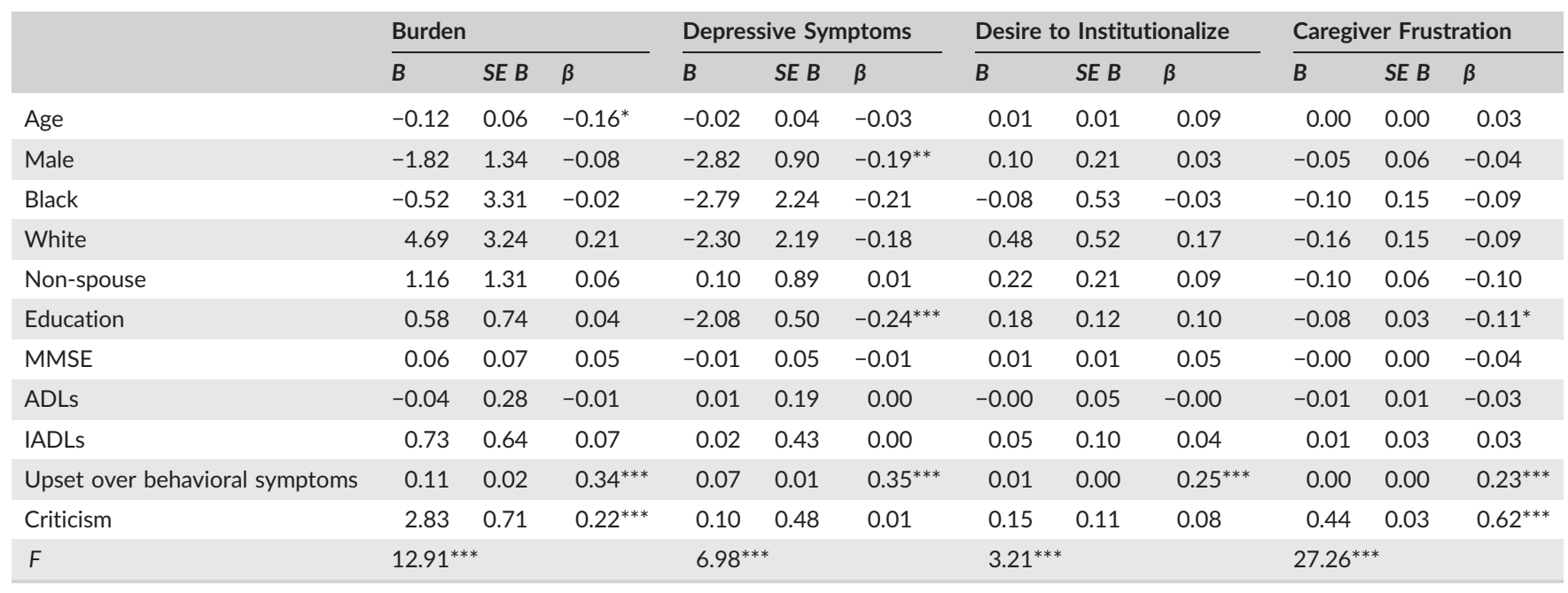

${ }^{a} \mathrm{n}=256$.

${ }^{*} P<0.05,{ }^{* *} P<0.01,{ }^{* * *} P<0.001$.

TABLE 3 Predictors of home, social, and health services among caregivers for persons living with dementia ${ }^{a}$

\begin{tabular}{|c|c|c|c|c|c|c|c|c|c|}
\hline & \multicolumn{3}{|c|}{ Home Services Utilization } & \multicolumn{3}{|c|}{ Social Services Utilization } & \multicolumn{3}{|c|}{ Health Services Utilization } \\
\hline & B & SE B & $\beta$ & $B$ & SE B & $\beta$ & $B$ & SE B & $\beta$ \\
\hline Age & 0.02 & 0.01 & $0.26^{* *}$ & -0.01 & 0.01 & -0.07 & -0.01 & 0.01 & -0.05 \\
\hline Black & 0.40 & 0.42 & 0.18 & 0.74 & 0.47 & 0.29 & 0.18 & 0.57 & 0.06 \\
\hline White & 0.35 & 0.41 & 0.16 & 0.60 & 0.46 & 0.24 & 0.48 & 0.55 & 0.17 \\
\hline MMSE & -0.01 & 0.01 & -0.04 & -0.01 & 0.01 & -0.07 & 0.02 & 0.01 & 0.14 \\
\hline ADLs & 0.10 & 0.04 & $0.23^{* *}$ & 0.03 & 0.04 & 0.05 & -0.02 & 0.05 & -0.03 \\
\hline IADLs & -0.02 & 0.08 & -0.02 & 0.11 & 0.09 & 0.09 & 0.11 & 0.11 & 0.08 \\
\hline Upset over behavioral symptoms & -0.00 & 0.00 & -0.03 & -0.01 & 0.00 & $-0.18^{* *}$ & -0.00 & 0.00 & -0.03 \\
\hline
\end{tabular}

${ }^{a} \mathrm{n}=256$.

${ }^{*} P<0.05,{ }^{* *} P<0.01,{ }^{* * *} P<0.001$.

recipient's illness tended to have higher expressed emotion, and expressed emotion was associated with worse quality of life for caregivers. As criticism and hostility are facets of expressed emotion, it may be that stigma is associated with the use of criticism as a management strategy as well. Indeed, in the current study, criticism was associated with greater subjective appraisals of burden and frustration in care, though unassociated with more objective measures of desire to place the PLWD in a nursing home or caregiver depression. Practically, efforts to reduce stigma and help caregivers normalize behavioral problems and attribute them to dementia, and not the PWDs character, may help to reduce the expressed criticism and improve quality of life.

\subsection{Criticism and service use}

If criticism is a reflection of frustration related to care or a strategy utilized due to a lack of other more adaptive management strategies, it may follow that a caregiver would feel more burdened and seek more services to assist in care provision. Indeed, caregivers in the current study who displayed greater criticism were more likely to use more social and home-based services, potentially reflecting a need for greater support among this group of caregivers. It may be that caregivers using care strategies other than criticism were better able to adapt and manage without the use of supportive services. However, supportive home and social-based services such as respite care and meal services are positive supports for overloaded or burdened caregivers. For example, services such as respite care have shown powerful positive effects, even biologically, on the health and well-being of both caregivers and PLWDs. ${ }^{32,33}$ Therefore, increased service utilization among caregivers using criticism as a management strategy may be viewed as a positive outcome, and it may be posited that service use may decrease expressed criticism over time, a point for future study. 
Of note, caregivers' upset over behavioral symptoms was consistently associated with caregiver's quality of life outcomes, but negatively associated with social services utilization. Social services measured in the current study largely include respite care services, and prior work has shown that services such as adult day care lower care-related stressor exposure. ${ }^{34}$ Thus, we similarly see here less upset among caregivers using more social services. Further, in spite of our inclusion of demographic characteristics and PLWD clinical factors (eg, cognitive impairment, functional impairment), our models explained little of the variance in services use. While criticism was associated with home-based and social services, none of our covariates (caregiver demographics, PLWD cognitive and functional status, and caregiver upset over behavioral symptoms) predicted health services utilization. As our services measures incorporated services used by both the caregiver and care receiver, this variability may have complicated the model, and service utilization was already low in our sample. Further, other health-related need variables (eg, multimorbidity), not included in the current models, may have explained greater variance.

\section{3 | Limitations}

We examined criticism and its associations in a sample of caregivers for persons in the moderate stage of dementia with reported behavioral problems. Thus, we do not know if criticism is used in equal measures among caregivers for individuals at other disease stages, whether criticism is an enduring management strategy, or if it arises with increased behavioral disturbances; these questions would be fruitful for future study. As analyses are not causal, it is unclear whether caregivers utilizing greater criticism may develop more burden and frustration, or whether burden and frustration led to the use of criticism, and future work should consider this question. We also could not determine whether the critical management strategy preceded service use. Likewise, it is unclear whether management strategies such as criticism are stable over time or whether change in strategy may impact outcomes such as utilization. The criticism subscale and frustrations of caregiving (use of harsh measures in care) were significantly correlated, and it is possible that they may make up a broader factor or style of caregiving such as an "authoritarian" or "disciplinarian" caregiving style (similar to the theories of parenting research); future studies may consider the classification of management strategies into broader caregiving styles. Given the nature of our services measure, we also could not distinguish between potentially preventable services utilization and necessary services utilization. Rates of depressive symptoms and other outcomes were relatively low suggesting that these findings may only generalize to a relatively well adapted group of caregivers.

In conclusion, in this sample of caregivers of persons at the moderate disease stage in which hands-on care management increases, we found that $15 \%$ of caregivers used criticism as a strategy to manage the behaviors of a PLWD and criticism was associated with caregiver's well-being and services utilization. Therefore, the strategies a caregiver uses to handle the unique context of dementia care are important to consider in addition to the more objective care context of dementia symptoms and decline. As depression, anger, and stress in caregivers have been associated with potentially harmful behavior toward PLWDs, it may be fruitful for researchers to consider whether criticism in and of itself has a harmful impact on PLWDs and when intervention may be indicated. ${ }^{35,36}$ Ultimately, as criticism is not likely to have an adaptive influence on PWDs and is associated with negative outcomes for caregivers, behavioral interventions that can help burdened caregivers learn how to manage behavioral symptoms and other stressful aspects of care with positive, empirically validated strategies may be helpful.

\section{ACKNOWLEDGEMENTS}

Support for this work was provided by the Program for Positive Aging at the University of Michigan. The original trial reported here was supported by the National Institute on Aging (NIA) and the National Institute on Nursing Research Grant (R01 AG22254 and clinical trial NCT00259480). Dr Leggett is funded by an NIA K01 Career Development award K01AG056557.

\section{CONFLICT OF INTEREST}

None declared.

\section{ORCID}

Amanda N. Leggett (D) https://orcid.org/0000-0001-7895-3862

\section{REFERENCES}

1. Alzheimer's Association. Alzheimer's disease facts and figures. Alzheimers Dement. 2017;13:325-373.

2. Lim J, Griva K, Goh J, Chionh HL, Yap P. Coping strategies influence caregiver outcomes among Asian family caregivers of persons with dementia in Singapore. Alzheimer Dis Assoc Disord. 2011;25(1):34-41.

3. Cooper C, Katona C, Orrell M, Livingston G. Coping strategies, anxiety and depression in caregivers of people with Alzheimer's disease. Int $J$ Geriatr Psychiatry. 2008;23(9):929-936.

4. Gottman JM. What Predicts Divorce? Hillsdale, NJ: Lawrence Erlbaum Associates; 1994.

5. Brown CR. The discovery of expressed emotion: induction or deduction? In: Expressed Emotion in Families: Its Significance for Mental Illness. New York: The Guilford Press; 1985:7-25.

6. Li C-Y, Murray M. A review of conceptualisation of expressed emotion in caregivers of older adults with dementia. J Clin Nurs. 2015; 24(3-4):332-343.

7. Tarrier N, Barrowclough C, Ward J, Donaldson C, Burns A, Gregg L. Expressed emotion and attributions in the carers of patients with Alzheimer's disease: the effect on carer burden. J Abnorm Psychol. 2002;111(2):340-349

8. Vitaliano PP, Young HM, Russo J, Romano J, Magana-Amato A. Does expressed emotion in spouses predict subsequent problems among care recipients with Alzheimer's disease? J Gerontol. 1993;48(4): P202-P209.

9. Pinquart M, Sörensen S. Associations of stressors and uplifts of caregiving with caregiver burden and depressive mood: a meta-analysis. J Gerontol B Psychol Sci Soc Sci. 2003;58(2):P112-P128.

10. Hinrichsen GA, Niederehe G. Dementia management strategies and adjustment of family members of older patients. Gerontologist. 1994;34(1):95-102.

11. Scott J, Wiegand G, Niederehe G. Measuring Behavioral Problems and Dimensions of Family Caregiving in Senile Dementia. San Antonio: The Gerontological Society of America; November, 1984. 
12. Bakker C, de Vugt ME, van Vliet D, et al. Predictors of the time to institutionalization in young- versus late-onset dementia: results from the Needs in Young Onset Dementia (NeedYD) Study. J Am Med Dir Assoc. 2013;14(4):248-253.

13. Hong S-I, Luo N, Yap P. Maximizing a nurturing care style for persons with dementia: a person-centered analysis. Am J Geriatr Psychiatry. 2013;21(10):987-998.

14. Davis LL, Chestnutt D, Molloy M, Deshefy-Longhi T, Shim B, Gilliss CL. Adapters, strugglers, and case managers: a typology of spouse caregivers. Qual Health Res. 2014;24(11):1492-1500.

15. de Vugt ME, Stevens F, Aalten P, et al. Do caregiver management strategies influence patient behaviour in dementia? Int J Geriatr Psychiatry. 2004;19(1):85-92.

16. Gitlin LN, Winter L, Dennis MP, Corcoran M, Schinfeld S, Hauck WW. Strategies used by families to simplify tasks for individuals with Alzheimer's disease and related disorders: psychometric analysis of the Task Management Strategy Index (TMSI). Gerontologist. 2002;42(1):61-69.

17. Gill CE, Hinrichsen GA, DiGiuseppe R. Factors associated with formal service use by family members of patients with dementia. J Appl Gerontol. 1998;17(1):38-52.

18. Toseland RW, McCallion P, Gerber T, Banks S. Predictors of health and human services use by persons with dementia and their family caregivers. Soc Sci Med. 2002;55(7):1255-1266.

19. Hong S-I. Understanding patterns of service utilization among informal caregivers of community older adults. Gerontologist. 2010;50(1):87-99.

20. Maust DT, Kales HC, McCammon R, Blow FC, Leggett A, Langa K. Distress associated with dementia-related psychosis and agitation in relation to healthcare utilization and costs. Am J Geriatr Psychiatry. 2017;25(10):1074-1082.

21. Martindale-Adams J, Nichols LO, Zuber J, Burns R, Graney MJ. Dementia caregivers' use of services for themselves. Gerontologist. 2016;56(6):1053-1061.

22. Delfino Lais L, Komatsu Ricardo S, Komatsu C, Neri Anita L, Cachioni M. Path analysis of caregiver characteristics and neuropsychiatric symptoms in Alzheimer's disease patients. Geriatr Gerontol Int. 2018;0(0).

23. Gitlin LN, Winter L, Corcoran M, Dennis MP, Schinfeld S, Hauck WW. Effects of the home environmental skill-building program on the caregiver-care recipient dyad: 6-month outcomes from the Philadelphia REACH initiative. Gerontologist. 2003;43(4):532-546.

24. Teri L, Truax P, Logsdon R, Uomoto J, Zarit S, Vitaliano PP. Assessment of behavioral problems in dementia: the revised memory and behavior problems checklist. Psychol Aging. 1992;7(4):622-631.
25. Logsdon RG, Teri L, Weiner MF, et al. Assessment of agitation in Alzheimer's disease: the Agitated Behavior in Dementia Scale. J Am Geriatr Soc. 1999;47(11):1354-1358.

26. Folstein MF, Folstein SE, McHugh PR. "Mini-mental state". A practical method for grading the cognitive state of patients for the clinician. J Psychiatr Res. 1975;12(3):189-198.

27. Gitlin LN, Roth DL, Burgio LD, et al. Caregiver appraisals of functional dependence in individuals with dementia and associated caregiver upset psychometric properties of a new scale and response patterns by caregiver and care recipient characteristics. J Aging Health. 2005;17(2):148-171.

28. Morycz RK. Caregiving strain and the desire to institutionalize family members with Alzheimer's disease: possible predictors and model development. Res Aging. 1985;7(3):329-361.

29. Radloff L. The CES-D scale: a self-report depression scale for research in the general population. Appl Psychol Measur. 1977;1(3):385-401.

30. Zarit SH, Reever KE, Bach-Peterson J. Relatives of the impaired elderly: correlates of feelings of burden. Gerontologist. 1980;20(6): 649-655.

31. Weisman de Mamani A, Weintraub MJ, Maura J, Martinez de Andino A, Brown CA. Stigma, expressed emotion, and quality of life in caregivers of individuals with dementia. Fam Process. 2018;57(3):694-706.

32. Zarit SH, Kim K, Femia EE, Almeida DM, Savla J, Molenaar PC. Effects of adult day care on daily stress of caregivers: a within-person approach. J Gerontol B Psychol Sci Soc Sci. 2011;66(5):538-546.

33. Leggett AN, Zarit SH, Kim K, Almeida DM, Klein LC. Depressive mood, anger, and daily cortisol of caregivers on high- and low-stress days. J Gerontol B Psychol Sci Soc Sci. 2014.

34. Zarit SH, Kim K, Femia EE, Almeida DM, Klein LC. The effects of adult day services on family caregivers' daily stress, affect, and health: outcomes from the Daily Stress and Health (DaSH) study. Gerontologist. 2014;54(4):570-579.

35. Beach SR, Schulz R, Williamson GM, Miller LS, Weiner MF, Lance CE. Risk factors for potentially harmful informal caregiver behavior. J Am Geriatr Soc. 2005;53(2):255-261.

36. MacNeil G, gmacneil@sw.ua.edu, Kosberg JI, et al. Caregiver mental health and potentially harmful caregiving behavior: the central role of caregiver anger. Gerontologist 2010;50(1):76-86.

How to cite this article: Leggett AN, Kales HC, Gitlin LN. Finding fault: Criticism as a care management strategy and its impact on outcomes for dementia caregivers. Int J Geriatr Psychiatry. 2019;34:571-577. https://doi.org/10.1002/ gps.5052 